\title{
BRIEF
}

\section{Student Pharmacists' Attitudes Toward Suicide and the Perceived Role of Community Pharmacists in Suicidal Ideation Assessment}

\author{
Cortney M. Mospan, PharmD ${ }^{\mathrm{a}}$, Chris Gillette, $\mathrm{PhD}^{\mathrm{b}}$ \\ ${ }^{a}$ Wingate University School of Pharmacy, Wingate, North Carolina \\ ${ }^{\mathrm{b}}$ Wake Forest School of Medicine, Winston-Salem, North Carolina \\ Submitted March 6, 2019; accepted October 14, 2019; published May 2020.
}

Objective. To determine first-year Doctor of Pharmacy students' attitudes toward suicide and perceptions of the role of the pharmacist in assessing patients for suicidal ideation, and whether their previous pharmacy work experience influences these attitudes and perceptions.

Methods. An anonymous online survey was administered to first-year student pharmacists at one school of pharmacy in North Carolina. Measures included gender, previous community pharmacy work experience, personal contact with suicide, and score on the Attitudes Toward Suicide (ATTS) scale.

Results. Seventy-three student pharmacists (75\%) completed the survey. The vast majority (92\%) agreed or strongly agreed that suicide was a real disease. Similarly, most students (79\%) agreed or strongly agreed that pharmacists have a professional responsibility to assess for suicidal ideation. There was not a significant association between ATTS score and previous community pharmacy work experience nor the perceived pharmacist's role in assessing for suicidal ideation. Additionally, there was no association between ATTS score and personal contact with suicide.

Conclusion. First-year student pharmacists, while undecided on their personal attitudes toward suicide, overwhelmingly agreed that suicide is a disease and that pharmacists have an important role in assessing patients for suicidal ideation. Pharmacy schools should implement training programs to prepare student pharmacists to identify suicidal ideation, design interventions to address student pharmacists' personal beliefs that may impact their ability to provide patient care, and provide students with adequate support skills to care for patients experiencing mental health crises.

Keywords: attitudes towards suicide, student pharmacist, community pharmacist, suicide prevention, suicide

\section{INTRODUCTION}

Suicide is now the tenth leading cause of death in the United States. ${ }^{1}$ Screening for depression is recommended for all adults, regardless of mental health history. ${ }^{2}$ Yet only $2.3 \%-5 \%$ of adults are screened for depression, and depression is the most common diagnosis in people who die by suicide. ${ }^{3-5}$ Inadequate screening leaves many patients undiagnosed and without adequate support and treatment. Given the low prevalence of depression screening, it is not surprising that only half of individuals who die by suicide had a mental health diagnosis. ${ }^{6}$ Community pharmacists are the most accessible health care provider, providing a potential avenue for addressing the increasing trend of death by suicide and low identification of mental health diagnoses. $^{7}$

Corresponding Author: Cortney M. Mospan, Wingate University School of Pharmacy, 515 N. Main St., Wingate, NC 28174. Tel: 704-233-8329. Email:

c.mospan@wingate.edu.
For community pharmacists to address the suicide public health crisis, they must demonstrate competency in suicidal ideation assessment and prevention strategies and confidence in providing this service, and be committed to meeting this public health need. ${ }^{8}$ While adequate suicide prevention training for pharmacists and student pharmacists can address confidence and competence in assessment, it will not ensure that community pharmacists view mental health assessment as a professional responsibility and implement services in their practices. Pharmacists' and student pharmacists' attitudes towards mental health conditions have been described, but no studies have examined attitudes towards suicide or suicide prevention in student pharmacists in the United States. ${ }^{8-17}$

Mental health elective coursework and anti-stigma interventions have improved student pharmacists' perceptions of and attitudes toward depression and schizophrenia; however, there is a lack of data regarding suicide. ${ }^{12,13}$ Negative and stigmatizing pharmacist 


\section{American Journal of Pharmaceutical Education 2020; 84 (5) Article 7588.}

attitudes are internal barriers that decrease pharmacists' likelihood of providing mental health services to patients and present challenges for patients attempting to access care through their pharmacist. ${ }^{10,11}$ Pharmacists have more positive attitudes towards patients experiencing suicidal ideation when they have participated in suicide prevention training or desire to have direct involvement in suicide prevention. ${ }^{8,15,16}$ The importance of these attitudes must be understood by student pharmacists as gatekeeper attitudes towards suicide can affect health care providers' behavior toward patients at risk of attempting suicide. ${ }^{14,16,18}$ This is particularly important as student pharmacists have shown social distancing from patients with mental health conditions. ${ }^{19}$ Community pharmacists may encounter patients experiencing mental health needs, and personal attitudes could significantly impact patient care and access. ${ }^{11,20,21}$

The purpose of this research was to investigate firstyear Doctor of Pharmacy (PharmD) students' attitudes toward suicide and their perception of the community pharmacist's role in assessing for suicidal ideation, and to determine whether student pharmacists' previous pharmacy work experience is associated with these attitudes and perceptions.

\section{METHODS}

This study was deemed exempt by the Wingate University Research Review Board. An anonymous online survey was administered to student pharmacists $(n=98)$ enrolled in Patient and Inter-Professional Communications during the first professional (P1) year in April 2018. Informed consent was collected at the beginning of the survey. The survey was administered using Qualtrics (Provo, UT).

The following student pharmacist demographic characteristics were collected: gender identification, previous paid community pharmacy work experience, and type of previous paid community pharmacy work experience. Work experience was collected because prematriculation work experience has been shown to influence student pharmacists' development of professional identity and perceptions about their future career. ${ }^{22-24}$ Student pharmacists were asked about personal contact with suicide and perceptions of the role of pharmacists in the assessment of suicidal ideation. Participants then answered dichotomous (yes or no) questions. Students indicated their level of agreement about the role of community pharmacists in assessing suicidal ideation using a 5-point Likert scale (strongly agree to strongly disagree). As very few student pharmacists disagreed or strongly disagreed that community pharmacists do not have a professional responsibility to assess for suicidal ideation, this variable was dichotomized into agree vs undecided/does not agree for the bivariate analyses. Student pharmacists were also asked about perceptions of suicide and responded using a five-point Likert scale.

In the last section of the survey instrument, student pharmacists completed a modified version of the Attitudes Toward Suicide (ATTS) scale. The ATTS scale is a 39-item instrument that uses a five-point Likert-type response scale, ranging from strongly agree (5) to strongly disagree (1) for the first 36 questions. We reduced the ATTS scale from 39 to 22 questions to limit participant fatigue. The original ATTS scale has been shown to have low internal consistency reliability $(0.51$ and 0.60$) .{ }^{25}$ Twenty items were simply scored and two were reverse scored to calculate a summary score.

All analyses were completed using SAS, version 9.4 (Cary, NC). Descriptive statistics are provided for demographic characteristics. Assumptions of normality were examined for the ATTS scale and were violated; thus, nonparametric statistics were used for the bivariate relationship analyses. The internal consistency reliability of the ATTS scale was assessed using Cronbach alpha. Wilcoxon-Mann-Whitney tests were used to analyze the relationship between previous paid pharmacy work experience and ATTS score. Wilcoxon-Mann-Whitney tests were also used to assess whether there was a relationship between perceived role of a pharmacist in suicidal ideation and ATTS score. The Fisher exact test was used to evaluate the relationship between previous pharmacy work experience and the perceived role of the pharmacist in assessing for suicide ideation. An alpha level $<0.005$ was used to assess statistical significance.

\section{RESULTS}

The demographic characteristics of the first-year student pharmacist cohort are presented in Table 1. Seventy-three student pharmacists completed the survey ( $75 \%$ response rate). The average respondent was female and had paid experience working in a community pharmacy. Of those who had previous community pharmacy work experience, most $(n=30,63 \%)$ gained that experience in a chain pharmacy setting. Most student pharmacists reported that they had known someone who had expressed suicidal thoughts/plans/threats $(n=43,59 \%)$ as well as someone who had attempted suicide ( $\mathrm{n}=44,61 \%)$; however, the majority $(n=49,67 \%)$ did not know someone who had died by suicide. Although the majority of student pharmacists reported not knowing what Mental Health First Aid (MHFA) training was $(n=39,53 \%)$, a small proportion $(n=9,12 \%)$ had completed MHFA training.

Most student pharmacists agreed or strongly agreed that suicide and mental health diseases are real conditions $(n=67,92 \%)$ and that anyone can suffer from suicide 


\section{American Journal of Pharmaceutical Education 2020; 84 (5) Article 7588.}

Table 1. Demographics of First-Year Student Pharmacists Who Participated in a Survey to Determine Their Attitudes Toward Suicide and the Perceived Role of Community Pharmacists in Assessing Suicide Ideation $(\mathrm{N}=73)$

\begin{tabular}{lc}
\hline Variable & No. $(\mathbf{\%})$ \\
\hline Gender & 66 \\
$\quad$ Female & \\
Previous paid pharmacy experience & 66 \\
$\quad$ Yes & \\
Pharmacy practice location & 63 \\
Chain pharmacy & 2 \\
Mass merchant & 15 \\
Grocery store & 19 \\
Independent pharmacy & 2 \\
Other (clinic pharmacy) & \\
Pharmacy role & 58 \\
Intern & 40 \\
Technician & 2 \\
Clerk & \\
\hline
\end{tabular}

ideation $(n=68,93 \%)$. The median score on the ATTS scale was 69 ( $\mathrm{IQR}=7$, range: 57-102), indicating that student pharmacists were generally undecided on personal attitudes toward suicide. Internal consistency of the ATTS measure had a Cronbach alpha $=0.62$ (standardized), indicating less than optimal internal consistency.

The majority of student pharmacists $(n=58,79 \%)$ agreed or strongly agreed that pharmacists have a professional responsibility to assess for suicide ideation in their patients. However, most student pharmacists also thought that patients did not want to discuss suicide ideation with their pharmacist $(n=41,56 \%)$.

There was not a significant association between student pharmacists' having previous paid community pharmacy work experience and their ATTS score $(Z=$ $-1.20, p=.23)$. Similarly, there was not a significant relationship between student pharmacists' work experience and perceived role of the pharmacist in assessing patients for suicide ideation $(p=.27)$. There was not a significant relationship between those who agreed that pharmacists should assess patients for suicide ideation and ATTS score $(\mathrm{Z}=1.08, p=.28)$. There were no significant associations between personal contact with suicide and ATTS score $(p>.005)$ or completion of MHFA and ATTS score $(p>.005)$. There were no significant relationships between perceived role of the pharmacist and personal contact with suicide $(p>.005)$.

\section{DISCUSSION}

First-year student pharmacists generally endorsed positive views towards their future role in identifying suicidal ideation and addressing patient mental health needs; however, a minority of licensed pharmacists in North Carolina felt that suicidal ideation assessment was a professional responsibility, with only $12 \%$ assessing patients for suicidal ideation. ${ }^{26}$ First-year student pharmacist attitudes towards suicide were generally undecided. These attitudes are important to understanding gatekeeper behavior and may function as guidelines for decision making. ${ }^{27,28}$ Further, there was no difference in ATTS scores between first-year student pharmacists who viewed suicide ideation assessment as a professional responsibility and those who did not. This suggests the factors that influence first-year student pharmacists' attitudes towards suicidal ideation and professional responsibilities are complex and must be researched further before optimal educational interventions can be designed.

Despite a professional commitment to patients' mental health, the majority of first-year student pharmacists felt that patients do not want to discuss suicidal ideation with community pharmacists. Patient self-stigma and limited awareness of pharmacist services may limit discussions about mental health with their pharmacist. ${ }^{29-33}$ However, patients have also reported having higher expectations for their community pharmacist's role in their mental health than is what is typically received, noting their community pharmacist can be a critical health care provider when their prescriber is inaccessible. ${ }^{32}$ This view is not universal though as some patients still perceive their community pharmacist as having a limited role in their mental health care. ${ }^{33}$

Key factors that improve patient comfort and willingness to discuss their mental health include having a private location in which to talk with their pharmacist, having a good rapport and trusting relationship with their pharmacist, and having a pharmacist who is willing to engage $^{30-32}$ To increase patient comfort with discussing mental health conditions with their pharmacist, patients have reported a desire that pharmacists have more education in how to explain mental health conditions and medications to them and more training in how to engage with patients in a non-demeaning fashion. ${ }^{29}$ While only one state currently requires that pharmacists receive training in suicide prevention, there are multiple programs available with a variety of delivery methods (eg, online, in-person, written). ${ }^{34}$

Community pharmacists have reported the most common barrier to assessing suicidal ideation is a lack of education and feeling unprepared to help patients who may be experiencing suicidal ideation. ${ }^{8,26}$ Further, studies have shown that pharmacists endorse more positive attitudes toward counseling patients with suicidal ideation following completion of suicide prevention training. ${ }^{8.15 .16}$ Pharmacists having negative and stigmatizing attitudes towards mental health decreases the likelihood that they will engage with patients in need and provide 


\section{American Journal of Pharmaceutical Education 2020; 84 (5) Article 7588.}

mental health services. ${ }^{10,11,19}$ Without further educational intervention, first-year student pharmacists may migrate from their undecided attitudes into more negative attitudes. If pharmacists are to be more involved in mental health care screening and subsequent care, student pharmacists and pharmacists will likely need more education to address the disparity among students regarding their perceived role in suicidal ideation assessment.

Another key finding of this study was low prevalence of both awareness and completion of MHFA training among first-year student pharmacists. The MHFA training reduces mental health stigma, improves mental health literacy, and increases pharmacists' intentions to provide first aid to patients experiencing mental health crises. ${ }^{35-38}$ Calls have been made for community pharmacists and student pharmacists to be required to complete MHFA training. ${ }^{39,40}$ While MHFA alone is likely insufficient, it is an evidencebased foundation on which to build as schools and colleges of pharmacy identify best practices. Within the American Pharmacists Association, the House of Delegates of the Academy of Student Pharmacists passed a resolution in 2017 calling for mental health educational reform. The resolution advocated for education regarding caring for patients with mental health conditions and appropriate methods of intervention (eg, crisis hotlines, local community resources, referral services) to reduce mental health stigma and address lack of confidence in care provision. ${ }^{40}$

This study does have limitations that should be considered. The study only represents a small cohort of one class of student pharmacists from one institution, which may limit generalizability. Student pharmacists' perceptions about the role of the pharmacist in suicide ideation assessment could vary based on their professional year in the PharmD program. Additionally, the exposure of the student pharmacists in this study to specific curricular content and student organizations could have influenced their responses. A validated measure based on the ATTS was used in the study to evaluate student pharmacists' attitudes toward suicide; however. it was shortened because of concerns over survey fatigue and, as a result, had a less than optimal internal consistency. Nevertheless, the internal consistency was similar to that of the original version of the instrument. Furthermore, additional questions were added to the survey that were not validated but were reviewed by two board-certified psychiatric pharmacists to ensure the content was valid and relevant for the study population.

\section{CONCLUSION}

A cohort of first-year student pharmacists overwhelmingly agreed that suicide is a disease and viewed pharmacist intervention for patients experiencing suicide ideation as a professional responsibility. However, student pharmacists were generally undecided on their personal attitudes towards suicide and believed that patients' lack of willingness to communicate with pharmacists about mental health was a barrier to intervention. Training programs need to be developed to prepare student pharmacists to identify suicidal ideation, to offer adequate support, and to patients experiencing suicidal ideation. Additionally, interventions to address personal beliefs that may impact patient care are likely needed. Future research is needed to better understand pharmacists' and student pharmacists' attitudes towards suicide.

\section{ACKNOWLEDGMENTS}

The authors thank Drs. Jerry McKee and P. Brittany Vickery for their careful review of our survey for face and content validity.

\section{REFERENCES}

1. Centers for Disease Control and Prevention. CDC Newsroom: Suicide rates rising across the U.S. https://www.cdc.gov/media/ releases/2018/p0607-suicide-prevention.html. Published June 7, 2018. Accessed May 14, 2020.

2. US Preventative Services Task Force. Final recommendation statement depression in adults: Screening. https:// www.uspreventiveservicestaskforce.org/Page/Document/ RecommendationStatementFinal/depression-in-adults-screening1. Published January 26, 2016. Accessed May 14, 2020.

3. American Psychiatric Association. Depression screening rates in primary care remain low. https://www.psychiatry.org/newsroom/ news-releases/depression-screening-rates-in-primary-care-remainlow. Published February 15, 2017. Accessed May 14, 2020. 4. Harrison DL, Miller MJ, Schmitt MR, Touchet BK. Variations in the probability of depression screening at community-based physician practice visits. Prim Care Companion J Clin Psychiatry. 2010;12(5):PCC.09m00911.

5. Hawton K, Casañas I, Comabella C, Haw C, Saunders K. Risk factors for suicide in individuals with depression: A systematic review. J Affect Disord. 2013;147(1-3):17-28.

6. Ahmedani BK, Simon GE, Stewart C, et al. Health care contacts in the year before suicide death. J Gen Intern Med. 2014;29(6):870-887.

7. Moose J, Branham A. Pharmacists as influencers of patient adherence. https://www.pharmacytimes.com/publications/directionsin-pharmacy/2014/august2014/pharmacists-as-influencers-of-patientadherence-. Published August 21, 2014. Accessed May 14, 2020. 8. Cates ME, Cochran Hodges JR, Wooley TW. Pharmacists' attitudes, interest, and perceived skills regarding suicide prevention. Ment Health Clin. 2019;9(1):30-35.

9. Watkins A, McKee J, Hughes C, Pfeiffenberger T. Community pharmacists' attitudes toward providing care and services to patients with severe and persistent mental illness. J Am Pharm Assoc. 2017;52(3S):S217-S224.e2.

10. Rickles NM, Dube GL, McCarter A, Olshan JS. Relationship between attitudes towards mental illness and provision of pharmacy services. J Am Pharm Assoc. 2010;50(6):704-713.

11. Calogero S, Caley CF. Supporting patients with mental illness: Deconstructing barriers to community pharmacist access. $J \mathrm{Am}$ Pharm Assoc. 2017;57(2):248-255. 


\section{American Journal of Pharmaceutical Education 2020; 84 (5) Article 7588.}

12. Gable KN, Muhlstadt KL, Celio MA. A mental health elective to improve pharmacy students' perspectives on mental illness. Am J Pharm Educ. 2011;75(2):Article 34.

13. Bamgbade BA, Ford KH, Barner JC. Impact of a mental illness stigma awareness intervention on pharmacy student attitudes and knowledge. Am J Pharm Educ. 2016;80(5):Article 80.

14. Boukouvalas EA, El-Den S, Chen TF, et al. Confidence and attitudes of pharmacy students towards suicidal crises: patient simulation using people with a lived experience. Soc Psychiatry Psychiatr Epidemiol. 2018;53(11):1185-1195.

15. Cates ME, Thomas AC, Hughes PJ, Woolley TW. Effects of focused continuing pharmacy education on pharmacists' attitudes toward suicide prevention. Pharm Educ. 2017;17:335-340.

16. Kodaka M, Inagaki M, Yamada M. Factors associated with attitudes toward suicide: Among Japanese pharmacists participating in the board-certified psychiatric pharmacy specialist seminar. Crisis. 2013;34(6):420-427.

17. Hanna LA, Bakir M, Hall M. UK pharmacy students' opinions on mental health conditions. Am J Pharm Educ. 2018;82(7):Article 6560 .

18. Neimeyer RA, Fortner B, Melby D. Personal and professional factors and suicide intervention skills. Suicide Life Threat Behav. 2001;31(1):71-82.

19. Seaton V, Piel M. Student pharmacists' social distancing toward people with mental illness. Ment Health Clin. 2017;7(5):181-186. 20. Murphy AL, Gardner DM, Chen TF, O'Reilly C, Kutcher SP. Community pharmacists and the assessment and management of suicide risk. Can Pharm J (Ott). 2015;148(4):171-175.

21. Murphy AL, Hillier K, Ataya R, et al. A scoping review of community pharmacists and patients at risk of suicide. Can Pharm $J$ (Ott). 2017;150(6):366-379.

22. Bloom TJ, Smith JD, Rich W. Impact of pre-pharmacy work experience on development of identity in student pharmacists. $\mathrm{Am} \mathrm{J}$ Pharm Educ. 2017;81(10):Article 6141.

23. Siracuse MV, Schondelmeyer SW, Hadsall RS, Schommer JC. Third-year pharmacy students' work experience and attitudes and perceptions of the pharmacy profession. Am J Pharm Educ. 2008;72(3):Article 50.

24. Siracuse MV, Clark BE. Third-year pharmacy students' work experiences and attitudes. Innov Pharm. 2017;8(2):Article 16.

25. Renberg ES, Jacobsson L. Development of a questionnaire on attitudes towards suicide (ATTS) and its application in a Swedish population. Suicide Life Threat Behav. 2003;33(1):52-64.

26. Gillette C, Mospan CM, Benfield M. North Carolina community pharmacists' attitudes about suicide and willingness to conduct suicidal ideation assessment: A cross-sectional survey study. Res Soc Admin Pharm. 2020;16(5):727-731.
27. Ji NJ, Hong YP, Lee WY. Comprehensive psychometric examination of the attitudes towards suicide (ATTS) in South Korea. Int J Ment Health Syst. 2016;10:2.

28. Stecz P. Psychometric evaluation of the questionnaire on attitudes towards suicide (ATTS) in Poland. Curr Psychol. 2019; doi: 10.1007/s12144-019-00185-1.

29. Knox K, Fejzic J, Mey A, et al. Mental health consumer and caregiver perceptions of stigma in Australian community pharmacies. Int J Soc Psychiatry. 2014;60(6):533-543.

30. Murphy AL, Phelan H, Haslam S, Martin-Misener R, Kutcher SP, Gardner DM. Community pharmacists' experiences in mental illness and addictions care: a qualitative study. Subst Abuse Treat Prev Policy. 2016;11:6.

31. Murphy AL, Gardner DM, Martin-Misener R, Naylor T, Kutcher SP. Partnering to enhance mental health care capacity in communities: A qualitative study of the More than Meds program. Can Pharm J (Ott). 2015;148(6):314-324.

32. Murphy AL, Martin-Misener R, Kutcher SP, O'Reilly CL, Chen $\mathrm{TF}$, Gardner SM. From personal crisis care to convenience shopping: An interpretive description of the experiences of people with mental illness and addictions in community pharmacies. BMC Health Serv Res. 2016;16(1):569.

33. Mey A, Knox K, Kelly F, et al. Trust and safe spaces: Mental health consumers' and carers' relationships with community pharmacy staff. Patient. 2013;6(4):281-289.

34. Carpenter DM, Lavigne JE, Roberts CA, Zacher J, Colmenares EW. A review of suicide prevention programs and training policies for pharmacists. J Am Pharm Assoc. 2018;58(5):522-529.

35. Morgan AJ, Ross A, Reavley NJ. Systematic review and metaanalysis of Mental Health Frist Aid training: Effects on knowledge, stigma, and helping behavior. PLoS One. 2018;13(5):e0197102.

36. Burns S, Crawford G, Hallett J, Hunt K, Chih JH, Tilley PJ. What's wrong with John? A randomized controlled trial of mental health first aid (MHFA) training with nursing students. BMC Psychiatry. 17(1):111.

37. McCormack Z, Gilbert JL, Ott C, Plake KS. Mental health first aid training among pharmacy and other university students and its impact on stigma toward mental illness. Curr Pharm Teach Learn. 2018;10(10):1342-1347.

38. Banh MK, Chaikind J, Robertson HA, et al. Evaluation of mental health first aid USA using the mental health beliefs and literacy scale. Am J Health Promot. 2019;33(2):237-247.

39. McKee J, Mospan CM, Benfield M, Gillette C. A call for community pharmacists to complete mental health first aid training. $J$ Am Pharm Assoc. 2019;59(2):167.

40. Simmons A. The mental health community: An underserved and undertreated population: Students call for increased efforts to reduce mental health stigma. J Am Pharm Assoc. 2017;57(6):649-650. 